without TNF $\alpha$ (100 U/ml for 30 minutes) and examined for ROS production (lucigenin emiluminescence) and MAPK activation (Western blot). Compared with cells transfected with an empty vector control) or cells transfected with wild-type p47phox (overexpression), S303/304A mutation had no significant effect on the basal level (without TNF $\alpha$ ) of ROS production. When cells were stimulated with TNFo, there was a twofold increase in ROS production by control and p47phox overexpressed cells. TNF $\alpha$ induced ROS production was significantly reduced $(\sim 60 \%)$ in cells transfected with the S303/304A mutation. However, there was no significant difference in TNF $\alpha$-induced phosphorylation of ERK1/2, p38MAPK and JNK between controls and the cells transfected with the S303/304A mutation. In conclusion, p47phox phosphorylation at S303/S304 plays an important role in TNF $\alpha$-induced ROS production, but is not involved in TNF $\alpha$-induced MAPK activation.

\section{NEURONAL NITRIC OXIDE SYNTHASE-MEDIATED REGULATION OF MYOCARDIAL REDOX STATE AND $\beta 3$ ADRENERGIC RECEPTOR RESPONSES}

doi:10.1136/hrt.2009.191049h

W Idigo, Y H Zhang, S Reilly, M H Zhang, M Crabtree, N Alp, B Casadei. Department of Cardiovascular Medicine, University of Oxford, John Radcliffe Hospital, Oxford, UK

Recent evidence suggests that increased superoxide production may decrease the bioavailability of endothelial nitric oxide synthase (eNOS)-derived nitric oxide in the myocardium of neuronal nitric oxide synthase $(\mathrm{nNOS})^{-/-}$mice. To test the functional relevance of this observation, we compared the eNOS-dependent inotropic and $\left[\mathrm{Ca}^{2+}\right]_{\mathrm{i}}$ transient effect of beta3-adrenergic receptor ( $\beta 3$-AR) stimulation in left ventricular myocytes from $\mathrm{eNOS}^{-/-}$and $\mathrm{nNOS}^{-1-}$ mice and their wild-type littermates. $\beta 3$-AR stimulation (with BRL $37344,10 \mu \mathrm{mol} / 1$ in the presence of the $\beta 1$ and $\beta 2$-AR blocker nadolol, $10 \mu \mathrm{mol} / \mathrm{l})$ resulted in a significant reduction in cell shortening and $\left[\mathrm{Ca}^{2+}\right]_{\mathrm{i}}$ transient amplitude in wild-type myocytes. In contrast, BRL plusnadolol had no effect in myocytes from $\mathrm{eNOS}^{-/-}$ and $\mathrm{nNOS}^{-1-}$ myocytes (in the absence of changes in $\beta 3-\mathrm{AR}$ messenger RNA levels or in eNOS protein expression in the latter) or in $\mathrm{nNOS}^{+/+}$myocytes pretreated with the nNOS-specific inhibitor, SMTC $(0.1 \mu \mathrm{mol} / \mathrm{l})$. Inhibition of xanthine oxidoreductase (XOR) or $\mathrm{NADPH}$ oxidases caused a similar reduction in basal superoxide production in $\mathrm{nNOS}^{-/-}$myocytes; however, whereas apocynin had no effect, XOR inhibition restored the negative inotropic response to $\beta 3-\mathrm{AR}$ stimulation in $\mathrm{nNOS}^{-/-}$myocytes but not in $\mathrm{eNOS}^{-/-}$ myocytes. eNOS activity was uncoupled in the myocardium of $\mathrm{nNOS}^{-1-}$ mice in the absence of changes in $\mathrm{BH} 4$ and biopterin levels or arginase activity. However, L-arginine transport was impaired in $\mathrm{nNOS}^{-/-}$myocytes and excess L-arginine $(10 \mathrm{mmol} / \mathrm{l})$ restored the response to $\beta 3$-AR stimulation. In summary, increased superoxide production by XOR (but not by NADPH oxidase) selectively abolished the negative inotropic effect of $\beta 3-\mathrm{AR}$ stimulation in $\mathrm{nNOS}^{-/-}$ myocytes by decreasing L-arginine transport and the bioavailability of eNOS-derived nitric oxide. These findings demonstrate that the source and subcellular localisation ofsuperoxide production can account for the diverse and specialised actions of reactive oxygen species in the heart.

\section{ENDOTHELIAL-SPECIFIC OVEREXPRESSION OF NOX2 ENHANCES ANGIOTENSIN II-INDUCED CARDIAC DYSFUNCTION AND FIBROSIS}

doi:10.1136/hrt.2009.191049i

${ }^{1} \mathrm{C}$ E Murdoch, ${ }^{1} \mathrm{~A}$ Brewer, ${ }^{1} \mathrm{M}$ Zhang, ${ }^{2} \mathrm{D}$ Vanhoutte, ${ }^{2} \mathrm{~S}$ Heymans, ${ }^{1} \mathrm{~A}$ M Shah. ${ }^{1}$ King's College, London, UK; ${ }^{2}$ University Hospital, Maastricht, The Netherlands

Nox2-containing NADPH oxidases are reported to be involved in the development of cardiac fibrosis in response to chronic angiotensin II infusion, but the cellular source(s) of Nox2 involved in fibrosis remains unclear. We investigated the role of endothelial Nox2 in angiotensin II-induced left ventricular hypertrophy (LVH). Male transgenic mice with endothelial-specific overexpression of Nox2 were compared with matched wild-type (wt) littermates after angiotensin II $(1.1 \mathrm{mg} / \mathrm{kg}$ per day) or saline infusion for 14 days. Basal blood pressure and left ventricular NADPH oxidase activity were similar in wt and transgenic mice. After angiotensin II infusion, both wt and transgenic groups developed similar hypertension $(170.2 \pm 11.6$ vs $170.4 \pm 12.3 \mathrm{~mm} \mathrm{Hg} ; \mathrm{n}=10)$ and hypertrophy (left ventricular/body weight ratio $4.8 \pm 0.2$ vs $4.7 \pm 0.2 \mathrm{mg} / \mathrm{g}$; and echocardiographic septal thickness increased by $34 \%$ wt and $37 \%$ transgenic mice; $n>10)$. NADPH oxidase activity was higher in angiotensin II-infused transgenic compared with wt left ventricles $(p<0.05)$. Interestingly, transgenic hearts showed significantly more interstitial cardiac fibrosis $(2.3 \pm 0.5$ vs $1.3 \pm 0.1 \%$ by Sirius red staining; $\mathrm{p}<0.05 ; \mathrm{n}=6$ ). In concurrence with a greater increase in inflammatory cell infiltration in transgenic left ventricles compared with wt $(55 \%$ increase in CD45 staining; $p<0.05 ; n=6$ ). Left ventricular systolic function assessed in vivo by left ventricular pressure-volume analysis was similar in both angiotensin II groups (ESPVR, 8.9 \pm 0.7 in wt vs $8.9 \pm 1.3 \mathrm{~mm} \mathrm{Hg} / \mu \mathrm{l}$ in transgenic mice; $\mathrm{p}=\mathrm{ns} ; \mathrm{n}=10$ ), whereas diastolic stiffness increased significantly only in the angiotensin II transgenic group (EDPVR increased from $0.2 \pm 0.0$ to $0.5 \pm 0.1 \mathrm{~mm}$ $\mathrm{Hg} / \mu \mathrm{l}$ in transgenic mice; $\mathrm{p}<0.05$; and from $0.2 \pm 0.0$ to $0.3 \pm 0.0 \mathrm{~mm}$ $\mathrm{Hg} / \mu \mathrm{l}$ in wt; $\mathrm{n}=10$ ). These results indicate that endothelial-specific overexpression of Nox2 significantly enhances the development of angiotensin II-induced cardiac fibrosis and left ventricular diastolic dysfunction, independent of changes in hypertrophy.

Funding Supported by the British Heart Foundation.

\section{CARDIOMYOCYTE-SPECIFIC OVEREXPRESSION OF NOX4 ATTENUATES ADVERSE CARDIAC REMODELLING AFTER MYOCARDIAL INFARCTION}

doi:10.1136/hrt.2009.191049j

M Zhang, Y H Looi, A C Brewer, A M Shah. King's College London, BHF Centre of Excellence, The James Black Centre, London, UK

Background Reactive oxygen species (ROS) production is implicated in the development of cardiac remodelling after myocardial infarction (MI). NADPH oxidases are major sources of cardiovascular ROS, with cardiomyocytes expressing both Nox2 and Nox4 isoforms. We previously showed that Nox 2 contributes significantly to the processes underlying adverse cardiac remodelling and contractile dysfunction post-MI, but the effect of Nox4 remains unclear. The aim of this study was to investigate the role of Nox4 in cardiac remodelling after MI.

Methods and Results We generated transgenic mice with cardiomyocyte-specific overexpression of Nox4, expressing the mouse fulllength Nox4 complimentary DNA under control of the $\alpha-\mathrm{MHC}$ promoter. Transgenic mice were backcrossed onto a C57BL6/J background and wild-type littermates (wt) used as controls. Nox4 transgenic mice were grossly similar to wt in terms of body weight, growth, activity, fertility and basal cardiac function. Transgenic mice displayed heart-specific expression of the Nox4 transgene, had significantly higher Nox 4 protein expression, over $60 \%$ higher heart $\mathrm{NADPH}$ oxidase activity and $42 \%$ increased hydrogen peroxide production (all $\mathrm{p}<0.05)$. Compared with wt, p22phox protein expression was increased by 2.4 -fold, which may be related to an increased protein stability. There was no change in the protein expression level of Nox2 or eNOS. MI was achieved by permanent left coronary ligation for 4 weeks. Compared with wt/MI, transgenic/MI groups displayed significantly high survival rate (72\% vs $95 \%$ ) and less hypertrophy at 4 weeks post-MI in terms of heart/ body weight ratio $(6.95 \pm 0.16$ vs $6.44 \pm 0.14, p<0.01)$, although the 